\title{
Discursos e práticas referentes ao processo de participação comunitária nas ações de educação em saúde: as ações de mobilização comunitária do PCDEN/PE
}

\author{
Discourses and practices concerning the social \\ participation process in health education activities: \\ community mobilization in the PCDEN/PE
}

Moab Duarte Acioli 1,3

Eduardo Freese de Carvalho 2,3

\footnotetext{
${ }^{1}$ Laboratório de Pesquisas em Psicologia Clínica, Centro de Filosofia e Ciências Humanas, Universidade Federal de Pernambuco. Rua Acadêmico Hélio Ramos, s/no, Cidade Universitária, Recife, PE, 50670-901, Brasil. 2 Departamento de Medicina Social, Centro de Ciências da Saúde, Universidade Federal de Pernambuco. Av. Moraes Rêgo, s/no, Cidade Universitária, Recife, $P E$ 50670-901, Brasil. 3 Núcleo de Estudos em Saúde Coletiva, Instituto Aggeu Magalhães. Rua dos Coelhos 450, 1o andar, Coelhos, Recife, PE 50070-550, Brasil.
}

\begin{abstract}
This study analyzes and compares several social participation concepts in health education processes to practical experiences with schistosomiasis prevention measures under the Northeast Endemic Disease Control Program (Brazilian Ministry of Health/World Bank, 1987). Using qualitative methods, institutional documents and discourses were interpreted (Sucam, FNS, and Ministry of Health). A field study was also performed (using interviews with community-based health agents and the general population) in the Zona da Mata region of Pernambuco (a historically endemic area for schistosomiasis), focused in the county of Amaraji. Comparing discourses and educational practices, we found factors that explain respective points of convergence and divergence, as well as elements linked to the social and historical process of the target population which systematically limit the efficacy of such educational measures.

Key words Health Education; Schistosomiasis; Consumer Participation; Community Participation

Resumo Neste artigo analisam-se alguns conceitos de participação comunitária nos processos de educação em saúde, contextualizando-os com as experiências práticas em relação às ações dirigidas para a esquistossomose dentro do Programa de Controle das Doenças Endêmicas do Nordeste (Ministério da Saúde do Brasil (MS)/Banco Mundial, 1987). Partindo-se de uma metodologia qualitativa, houve tanto a análise de discursos institucionais (Sucam, FNS e Ministério da Saúde), quanto um trabalho de campo (entrevistas com agentes de saúde e população) realizado na Zona da Mata de Pernambuco (historicamente endêmica) e, principalmente, no Município de Amaraji. Comparando-se discursos e práticas educativas, foram encontrados fatores responsáveis pelas respectivas convergências e divergências, assim como elementos vinculados ao processo social e histórico das populações envolvidas que limitam a eficácia das ações educativas, inclusive de uma maneira mais sistemática.
\end{abstract}

Palavras-chave Educação em Saúde; Esquistossomose; Participação Comunitária 


\section{Introdução}

Uma estratégia pedagógica que se destacou nos programas nacionais de controle das endemias, desde a passagem dos anos 80 para os anos 90, foi a mobilização comunitária. No presente artigo, procuraremos enfatizar as ações de informação/educação/comunicação e mobilização comunitária do Programa de Controle das Doenças Endêmicas do Nordeste (MS, 1987), especialmente em relação à endemia esquistossomótica na Zona Mata de Pernambuco, tendo por referência de campo, o Município de Amaraji.

Em linhas gerais, a ação educativa pode transcorrer por meio de métodos e técnicas que reproduzam ou não a estrutura ideológica e as relações sociais de dominação, podendo, então, ser caracterizadas como pedagogias transmissivas, de condicionamento ou da problematização, tanto em nível individual, quanto social. Problematizar, portanto, significa utilizar-se de elementos da realidade vivida para diagnosticar problemas comunitários e construir hipóteses, para, em seguida, aplicar uma solução viável, nos moldes de ação-reflexão-ação. Sua prática busca, enfim, uma transformação dessa mesma realidade social (Bordenave, 1980).

Existe uma estreita correlação entre a pedagogia da problematização e trabalhos de pesquisa que envolvam a participação da comunidade, denominando-se de pesquisas-participantes. São tentativas de se romper com o círculo vicioso em que as condições materiais de opressão, impotência e resignação mental se reforçam de tal maneira, que a dominação social e econômica é considerada simplesmente um fato normal e natural (Jara, 1995).

Outra denominação para as metodologias participativas é a pesquisa-ação, embasada no pressuposto de que todas as ações humanas guardam um maior ou menor contexto político, objetivando desenvolver práticas politicamente conscientes, no sentido de aliar conhecimentos e mudança social (Demo, 1995).

A presente linha conceitual foi incorporada às metas da Divisão Nacional de Educação em Saúde (DNES), do Ministério da Saúde, no final dos anos oitenta, num momento de redemocratização da sociedade brasileira. As ações específicas foram compreendidas como práticas sociais formadoras de consciência crítica a respeito dos problemas sanitários. Com isso, pretendia-se capacitar indivíduos e grupos para a transformação da realidade, respeitando-se o universo cultural das comunidades e se entendendo a prática pedagógica como dinâmica e participativa (MS, 1989b).
Portanto, o conceito de participação relaciona-se, estreitamente, com a idéia de cidadania, ao enfatizar a reividicação política, a democratização e a socialização do saber, das decisões e dos planejamentos das metas. A idéia de que a educação deveria ser uma interativa troca de conhecimentos permite resgatar filosofias que representam uma possibilidade de autonomia crítica do educando. Nessa perspectiva, cabe ressaltar a 'pedagogia da liberdade', considerando que "o aprendizado já é um modo de tomar consciência do real e como tal só pode dar-se dentro dessa tomada de consciência" (Freire, 1977:8).

A participação das comunidades nos processos de educação em saúde pode apresentar diversos modos dependentes das técnicas e dos objetivos intrínsecos. Assim, considera-se simbólica, quando a população é apenas incluída no processo, sem ação ativa, nem mesmo receptiva. Ela é receptiva quando existe o recebimento de algum serviço do Estado. A participação é ativa nas situações em que a população toma parte num conjunto de atividades não planejadas, nem programadas pelas comunidades, como no caso de mutirões e mobilizações. Por fim, a participação é real quando a população reividica e assume parte em processos que vão do diagnóstico, passam pelo planejamento, execução e avaliação das ações desenvolvidas (Pinto, 1982).

\section{Objetivos}

1) Avaliar as principais medidas programadas de controle da esquistossomose na Zona da Mata de Pernambuco.

2) Interpretar os resultados das ações educativas realizadas na área de estudo.

3) Refletir sobre o significado de mobilização comunitária tendo como base as avaliações das ações educativas referidas.

\section{Metodologia}

O presente estudo está centrado em informações indiretas e trabalho de campo. Esses dados foram obtidos e constituídos a partir de uma análise de conteúdo de documentos institucionais, tais como projetos, relatórios, diretrizes, tanto da Sucam e FNS em Pernambuco, quanto do nível central do Ministério da Saúde.

O trabalho de campo ocorreu mediante entrevistas semi-estruturadas com os agentes de saúde que atuaram na Zona da Mata, no período de 1990 a 1995. As entrevistas da população 
de Amaraji, por sua vez, foram realizadas entre julho e setembro de 1995, enquanto componente teórico e metodológico da pesquisa de avaliação das ações de controle da endemia esquistossomose, em Pernambuco (Freese-deCarvalho \& Acioli, 1996).

Amaraji é um pequeno município da Zona da Mata Sul de Pernambuco, com população de 19.943 habitantes, cujas atividades econômicas circulam em torno do plantio e da agro-indústria do açúcar, além de atividades comerciais.

\section{Proposta de mobilização comunitária nas ações IEC/MC/PCDEN (1989)}

O projeto Programa de Controle das Doenças Endêmicas do Nordeste (PCDEN) foi elaborado por um grupo de técnicos da Sucam para apresentação e aprovação de seu financiamento ao Banco Internacional de Reconstrução e Desenvolvimento (Bird), componente da Organização das Nações Unidas.

A concepção e objetivos do projeto nacional PCDEN (MS, 1987) visavam reforçar ações do governo brasileiro no controle de importantes endemias (esquistossomose, doença de Chagas e leishmaniose), por meio da implementação e expansão das operações de campo e de outras atividades da Sucam, fundamentandose em quatro componentes principais:

1) prevenção do controle da transmissão da doença (PCTD);

2) pesquisas operacionais (PO):

3) desenvolvimento institucional (DI);

4) mobilização comunitária (MC), definida como a conjunção do processo de informação, educação e comunicação (IEC), para a organização de grupos comunitários, objetivando participar na prevenção da doença e atividades de controle, inclusive redução de vetores.

Constatou-se, inclusive, que, em muitas localidades de alta endemicidade esquistossomótica, houve uma redução da prevalência e das formas graves (hepatoesplênicas). Entretanto, persistiam os casos positivos em níveis elevados, apontando-se como determinantes indiretos e diretos a ausência de descentralização e regionalização nos programas de controle, pouca participação da comunidade no combate à esquistossomose e a falta de um trabalho educativo que estimulasse a consciência e a atuação da população em relação às medidas preventivas, aos trabalhos de saneamento ambiental e à modificação de hábitos favorecedores da propagação da parasitose (MS, 1987).

No documento nacional do PCDEN (MS, 1987), apontava-se para o crescimento da posi- tividade das endemias. Em análise temporal realizada sobre a esquistossomose, constatouse uma oscilação com períodos de maiores e de menos índices, conforme está registrado na tabela 1 apresentada a seguir (Freese-de-Carvalho \& Acioli, 1996).

Nessa série temporal, a partir de 1977, ano do levantamento inicial do Programa Especial de Controle da Esquistossomose (Pece), verificaram-se os mais elevados índices de positividade do período. Em decorrência do observado, desencadeou-se um processo de intensa medicalização da população da Zona da Mata de Pernambuco. Conseqüentemente, observou-se nos anos 1980-1981 uma drástica redução dos índices de positividade. Nesses anos, verificaram-se os mais baixos índices de toda a série temporal estudada (1977-1994). Na fase pré-PCDEN (1985), observa-se um incremento nos índices de positividade, entretanto, com valores percentuais menores do que os verificados no início do programa (1977), porém mais elevados do que o dos anos precedentes. Este último fato constitui-se numa das justificativas do PCDEN. Em 1994, na fase pósPCDEN, destacou-se uma diminuição dos índices, também decorrente da medicalização, sem alcançar, porém, uma redução tão significativa quanto a observada nos anos de 19801981.

Assim, para os objetivos governamentais, mobilização comunitária era um trabalho educativo que objetivava reverter os índices de positividade, mediante a adoção, por parte dos indivíduos e comunidades, de uma série de comportamentos considerados adequados, para se modificar a situação das endemias em diversas localidades As estratégias escolhidas foram educação popular (envolvendo grupos escolares, institucionalizados e de diversas faixas etárias, contando-se com apoio de unidade móvel e material de apoio pedagógico); educação de massa (campanhas educativas através da mídia) e pesquisa participante (MS, 1987).

Tabela 1

Percentual de positividade (Kato-Katz) para esquistossomose em municípios da Zona da Mata, Sul de Pernambuco.

\begin{tabular}{lcccc}
\hline Municípios & 1977 & $\mathbf{1 9 8 0 / 1 9 8 1}$ & 1985 & 1994 \\
\hline Amaraji & $11,6 \%$ & $5,5 \%$ & $8,7 \%$ & - \\
Catende & $62,0 \%$ & $18,6 \%$ & $48,9 \%$ & $23,1 \%$ \\
Palmares & $41,1 \%$ & $12,8 \%$ & $21,7 \%$ & $11,9 \%$ \\
Belém de Maria & $59,3 \%$ & $10,0 \%$ & $32,3 \%$ & - \\
\hline
\end{tabular}

Fonte: Carvalho \& Acioli, 1996. 


\section{Desenvolvimento do programa de mobilização comunitária (IEC/MC/ PCDEN) em Pernambuco}

Em 1989, dois anos após o início do programa nacional, a Diretoria Regional da Sucam/PE elaborou o documento estadual do PCDEN. No projeto pernambucano, o conceito de mobilização comunitária apresentava algumas diferenças em relação ao nacional, pois, no caso, as atividades IEC/MC se caracterizavam pela difusão de conhecimentos através dos meios de comunicação de massa ou por grupos específicos; tais conhecimentos seriam incorporados pelos indivíduos na vida cotidiana. Nessa definição, a problemática era enfocada num viés individualizado e não coletivo e o processo educativo continuava a ser considerado sob uma perspectiva transmissiva, diferentemente da proposta de maior participação das comunidades, de acordo com o documento nacional (MS, 1989a).

Apesar de diversos empecilhos administrativos e burocráticos, a equipe de Educação em Saúde da Sucam planejou, para o ano de 1990, desenvolver um trabalho educativo em quatro Distritos Sanitários do Estado (Vitória de Santo Antão, Caruaru, Garanhuns e Salgueiro), dentro dos critérios de metodologia participativa do PCDEN. Tinha-se como objetivo uma cobertura de 258 municípios, com a presença das três endemias enfocadas, o que se caracterizou como uma meta ousada (MS, 1990).

É significativo registrar que no planejamento da equipe de Educação em Saúde da Sucam/ PE (MS, 1990), consideraram-se como estratrégias do PCDEN as melhorias das condições de saneamento e de habitação e como parâmetros avaliativos a prevalência de casos e a demanda da população aos serviços formais de saúde. Dessa forma, uma das funções do trabalho educativo era a de mobilizar e de motivar a população a se dirigir com maior regularidade aos serviços formais de saúde, diferentemente de uma conscientização crítica da realidade.

Outra dificuldade, em relação às ações IEC/ MC/PCDEN, foi a reermergência de epidemias aparentemente imprevisíveis, como o caso do cólera, em Pernambuco, no ano de 1992.

Sendo assim, para os objetivos do presente artigo é necessário saber: qual a prioridade das ações relativas às endemias/epidemias enfocadas? Quais foram as atividades educativas desenvolvidas? E quais meios auxiliares de ensino foram utilizados?

De acordo com os dados da Tabela 2, para o cólera foram dirigidas $96,55 \%$ das atividades educativas, diferentemente da esquistossomose, que, apesar de ser uma doença endêmica
Tabela 2

Atividades educativas no Distrito de Vitória de Santo Antão (1992).

$\%$

\begin{tabular}{lr}
\hline & $\%$ \\
\hline $\begin{array}{l}\text { Atividades educativas } \\
\text { dirigidas para endemias }\end{array}$ \\
Cólera & $96,55 \%$ \\
Esquistossomose & $1,95 \%$ \\
Leishmaniose & $1,45 \%$ \\
Filariose & $0,04 \%$ \\
& \\
Atividades educativas & \\
Visitas domiciliares & $63,75 \%$ \\
Entrevistas & $25,10 \%$ \\
Palestras & $11,01 \%$ \\
& \\
Meios auxiliares de ensino & \\
Distribuição de instrumentos & $53,22 \%$ \\
bioterápicos & \\
Material pedagógico & $46,78 \%$ \\
\hline
\end{tabular}

Fonte: MS, 1992.

naquele distrito, contou com apenas 1,95\% das atividades realizadas. Como atividades educativas, as visitas domiciliares foram as mais freqüentes, atingindo um percentual de $63,79 \%$, contra $25,1 \%$ de entrevistas e $11,01 \%$, de palestras. Essas ações educativas continuavam congruentes com o modelo de pedagogia transmissiva.

Outro detalhe aponta para a distribuição de instrumentos bioterápicos (hipoclorito de sódio, colher de medida, sais hidratantes), sendo considerados meios auxiliares de ensino, ocupando um percentual de 53,22\%. Por sua vez, folders, folhetos, cartazes, apostilas, boletins informativos e a locução de notas no rádio perfaziam 46,78\% do total. Dessa forma, além da priorização por medidas bioterápicas, as ações pedagógicas propriamente ditas resumiram-se a atividades informativas, sem referências a metodologias problematizadoras.

Considerando-se que os dados anteriores, em função da epidemia do cólera, poderiam ser interpretados como acidentais, procuraremos analisar, então, outros dados, aqueles das atividades educativas e de mobilização comunitária do Programa de Controle da Esquistossomose (PCE, incorporado ao PCDEN), entre o segundo semestre de 1993 e o primeiro semestre de 1994, também no Distrito de Vitória de Santo Antão (MS, 1993/1994), que engloba significativa área da Zona da Mata de Pernambuco (Tabela 3). 
Tabela 3

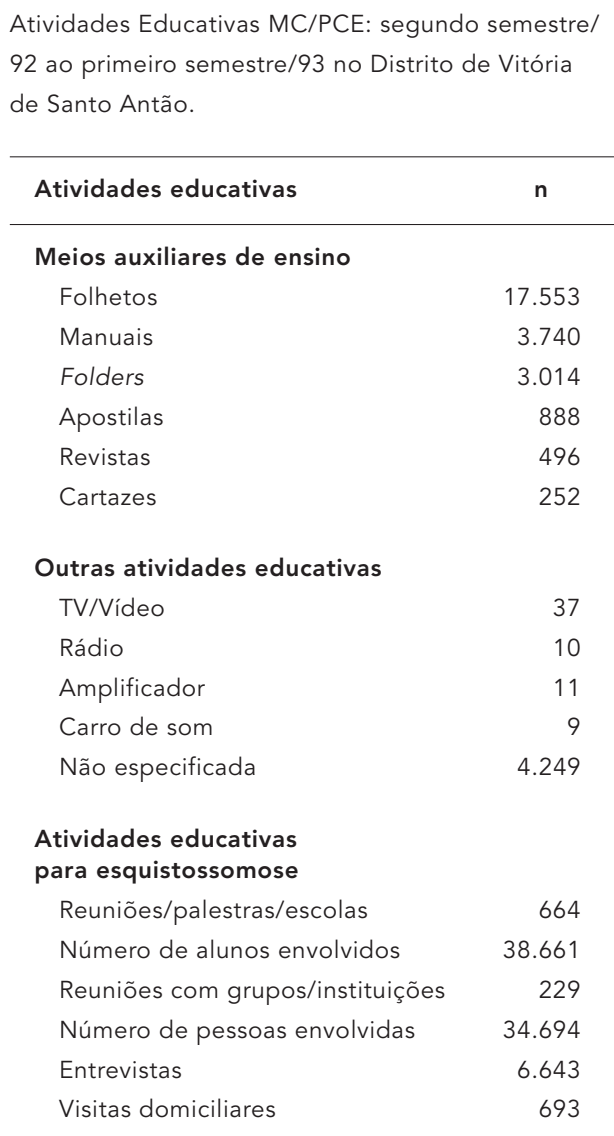

Fonte: MS, 1993/1994

Comentando os novos dados, observamos como meios auxiliares de ensino uma ampla distribuição de material pedagógico, principalmente folhetos e manuais. Além disso, no caso de municípios como Amaraji, de acordo com estudo de Freese-de-Carvalho \& Acioli (1996), a sede apresenta uma distribuição de $49,5 \%$ de população analfabeta e o Distrito de Demarcação, 60,4\%, o que limita a eficácia dessas ações.

Registram-se atividades de comunicação por meio do uso de vídeo, boletins em rádio, carros de som e de atividades não especificadas, que são referidos no relatório como atividades de mobilização comunitária. No relatório não se detectam contatos prévios com as comunidades, o que novamente caracteriza o total de dados e das atividades como sendo transmissivas.

Houve resistências e entraves institucionais para uma efetiva ação de mobilização comunitária, causados por conflitos entre o setor de Educação em Saúde e chefias institucionais e por carência de recursos humanos, em termos numéricos e de habilitação para o exercício da nova metodologia.

Tendo-se um perfil objetivo do processo de educação em saúde na Zona da Mata de Pernambuco, torna-se complementar e mais abrangente dispor-se de informações sobre o processo valendo-se das perspectivas de importantes atores sociais, como os agentes de saúde e a população municipal, no caso a de Amaraji.

\section{As ações de mobilização comunitária na perspectiva dos agentes de saúde da Sucam/FNS}

O trabalho dos agentes de saúde na área de educação teve por objetivo principal convencer a população da importância do uso dos remédios (Mansil), assim como evitar a utilização da água do rio. Essa constatação coadunase com relatório do PCE (MS, 1990), no qual se aponta para uma predominância de medicalização e ausência de registro de atividades educativas propriamente ditas (MS, 1990).

A concepção pedagógica naquele período consistia na transmissão das informações acerca da doença, suas conseqüências e formas de prevenção. Assim se posiciona um agente de saúde sobre a função de medicalizar: "Na parte de educação era mais assim, era facilitar o recebimento do Mansil. Porque existia uma equipe que fazia parte do laboratório, dos exames (...). A gente fazia essa parte de divulgação mais, do que era doença e orientando o pessoal a aceitar o medicamento (...). E tinha outra equipe que era os guardas-medicadores".

Dentro da cultura institucional da Sucam, os agentes de saúde passaram a ser conhecidos como guardas-educadores em contraposição aos tradicionais guardas de endemias. Pode-se destacar uma relação paradoxal entre os termos, já que, no primeiro, o substantivo significa 'quem vigia' e o adjetivo, 'quem promove o desenvolvimento físico, intelectual e moral'.

Pode-se observar, também, uma divisão de papéis entre os agentes de saúde. Um grupo responsável pelo trabalho divulgativo é classificado, informalmente, na instituição como guardas-educadores. Por sua vez, outro grupo, com função específica, é denominado guardasmedicadores.

De acordo com as informações dos técnicos, as atividades educativas consistiam em articulações com gestores do poder público, lideranças, igrejas, associações e palestras nas escolas com professores e alunos, tanto na zona urbana, como na rural, conforme se apreende 
no discurso de outro agente de saúde: "Inicialmente quando chegávamos em um município, entrávamos em contato com as lideranças. $O$ primeiro caminho era a prefeitura, depois era a secretaria de saúde, secretaria de educação e daí a gente partia para as escolas. Nas escolas, tanto a gente tinha palestras com os professores como com os alunos e com os pais. Igrejas também e assim em associações, todo grupo que existisse na localidade. Tanto na zona urbana, como na rural."

A equipe de educação em saúde (Sucam/ PE) encontrou dificuldades para implementar as ações e atingir os objetivos do PCE, em razão de empecilhos advindos da estrutura institucional, do processo de medicalização de massa e das condições objetivas de existência em população.

Institucionalmente, havia dificuldades com o transporte, alojamento e falta de material, solicitações que constavam em documentos oficiais (MS, 1990). Um outro fator apontado referia-se ao caráter itinerante das ações, o que dificultava a 'cristalização' das informações pelas comunidades. Foram também apontadas dificuldades com o paternalismo, gerador de conflitos com a equipe de educação em saúde, por conta da seleção de guardas-educadores, pois, muitas vezes, não eram cumpridos os objetivos do perfil ideal, atendendo-se às 'indicações' das chefias. Também são feitas observações sobre um certo 'verticalismo' presente na elaboração e execução das diretrizes. Sobre essas posturas, assim percebe outro agente de saúde: "Quando entrei, o meu trabalho era com a comunidade, mas para atingir um objetivo preestabelecido, que vinha de Brasília. As coordenações iam executar. Havia um planejamento feito pelos técnicos a nível das regionais, que elegia quais as cidades a serem trabalhadas. As coisas vinham de cima para baixo".

Em relação aos entraves provocados pela medicalização, os agentes de saúde apontam para os efeitos colaterais provocados pelo Mansil e o desconhecimento dos resultados dos exames parasitológicos pela população. Este fato causava descontentamento, uma vez que se ficava à espera de um resultado personalizado, e o que vinha era um tratamento em massa.

Foi relatada, também, a falta de saneamento básico e fornecimento de água nas comunidades, aliada às precárias condições materiais de existência. As populações eram obrigadas a fazer uso do rio, inclusive como estratégia de sobrevivência, na lavagem de roupa 'por ganho' e na pesca. Nesse sentido, a realidade concreta limitava a eficácia das orientações sobre a necessidade de evitar o uso do rio.
Dentro desse panorama, a participação comunitária ocorria apenas como uma forma de chamar a atenção do povo, mediante atividades descontínuas, já que eram organizadas por equipes itinerantes. Essas observações constam no discurso de outro agente de saúde: "Havia assim uma idéia de que mobilização era só passeata, gincana, só coisa desse tipo. Eles tinham muito essa idéia, mas a mobilização não era só isso. Era mais participação. A população assumir as necessidades e com suas próprias mãos caminhar, né? Procurar melhorar aquela situação. Mas a idéia ligada à mobilização era chamar a atenção do povo, numa passeata, numa coisa, mas não era só isso. Inclusive, também, quando surgia qualquer coisa assim, uma outra necessidade "x", aí íamos atuar em outra endemia, entendeu? Faltou muito assim, continuidade. Porque como se disse, né? Sempre fomos itinerantes. Então é impossível você fazer mobilização em um mês, né?".

De acordo com as referências bibliográficas, mobilização comunitária é uma atividade de participação das comunidades em ações não programadas pelos respectivos grupos (Pinto, 1982). Para os agentes de saúde, contudo, mobilização seria uma participação real, no sentido de as comunidades estarem incluídas em todas as fases do processo educativo, o que estratégica e teoricamente se considera como diagnóstico situacional, planejamento, execução e avaliação de programas comunitários. Existe, portanto, explicitamente, no discurso do agente de saúde, uma crítica às limitações da ação educativa, verticais e reprodutivistas, e uma consideração sistematizada não em termos de técnicas, mas de objetivos, no sentido de a população assumir responsabilidades na transformação da qualidade de vida.

Destaca-se que as ações educativas estão descontextualizadas da realidade concreta da população. Muitas vezes são executadas fora do contexto cotidiano das populações. Outras vezes, não atendem às necessidades básicas e nem solucionam os graves problemas relativos às precárias condições de saneamento, moradia, alimentação e trabalho. Essas observações constam na fala de outro agente de saúde: "Eles não tinham nem disponibilidade para estar se encontrando, participando de reuniões. Se a gente chamasse pra se reunir de manhã era improdutivo, porque ia fazer a comida do marido, ia para o trabalho, porque geralmente trabalhavam no campo. E quando a gente conseguia juntar um grupinho, era mais à tarde. À noite, já tinha dificuldades, por causa de televisão, não sei o quê (...). Aí, a pessoa ia a uma reunião, duas, tudo bem, mas a pessoa assumir aquilo, 
era muito difícil. A população não tinha disponibilidade pra tá atuando assim, nessa linha, porque o povo, de uma forma geral, gosta muito do concreto. Quando a gente chegava na reunião eles diziam: - Ah! Não acredito em blá, blá, blá.. O governo mandou feijão pra gente, e farinha, comida, remédio? - Eles queriam o real, o concreto".

As limitações das ações educativas causadas pelas concretas condições sócio-econômicas da população não eram devidamente avaliadas por conta de uma rotina de trabalho itinerante. Além disso, conforme foi analisado, por conta da verticalidade descontextualizada das ações educativas, muitas procuravam destacar objetivos pontuais, não considerando as necessidades econômicas, alimentares e de higiene da população, no caso, os banhos de rio, enquanto estratégias de sobreviência.

Além desses empecilhos, os agentes de saúde se queixavam da ausência de feed-back e de avaliação de resultados, conforme se constata no último discurso: "Outra coisa: você trabalhava num município e partia pra outro. Você não sabia nem o que houve, se a coisa continuou, se parou, não havia uma avaliação final, entendeu?".

Assim sendo, mobilização comunitária, no caso das ações IEC/PCDEN, caracterizava-se como estratégia pedagógica para se reverter históricos índices de positividade das endemias enfocadas, e, no caso específico da esquistossomose, os resultados não ocorreram satisfatoriamente.

Uma proposta teórica de participação ativa converteu-se nos moldes tradicionais de transmissão de informações, tendo por objetivo chamar a atenção da população para os problemas e soluções propostas pelas instituições oficiais. Enfatizam-se os limites das ações decorrentes das precárias condições materiais de existência da população e os aspectos estruturais dos serviços formais de saúde.

\section{As ações educativas na perspectiva da população de Amaraji}

A população do Município não relata ações voltadas para a esquistossomose no trabalho dos agentes de saúde. Fala-se de borrifação, verificação de existência de coleta de água, coleta de fezes, distribuição de remédios e fixação de croquis nas paredes. Os agentes também orientavam a população em termos de cuidados com a higiene e materno-infantis, notificando os casos de dengue nos domicílios e fazendo encaminhamento aos postos.
Os entrevistados também distinguem os guardas-educadores ("fazem apenas perguntas") dos guardas das endemias ("carregam remédios para matar os insetos”).

Em algumas localidades do Distrito de Demarcação, as mais pobres e de difícil acesso do município, observou-se que as visitas domiciliares foram tão espaçadas a ponto dos entrevistados não se recordarem, ocorreram há muito tempo, ou até mesmo, nunca foram realizadas.

A maior parte da população entrevistada negou ter participado de algum tipo de reunião ou mobilização sobre saúde. Em Demarcação, os que afirmaram ter freqüentado reuniões relativas à saúde disseram que "eram apenas $p a$ ra mulheres que tinham carteira de identidade e sabiam assinar o nome". Na reunião, além da distribuição de folhetos sobre saúde, foi "dado um envelope com dinheiro". Na sede do município, um reduzido número de entrevistados afirmou ter conhecimento de reuniões sobre educação em saúde, sem, entretanto, haver participado delas.

As ações de educação em saúde, seja mediante visitas dos agentes de saúde, seja pela distribuição dos panfletos, apesar de serem vistas como positivas pela população, são passíveis de críticas, pois o discurso institucional não leva em conta a objetiva falta de condições das populações para o cumprimento das propostas.

"Esses folheto tinha muita coisa (...) mas eu também num ligo muito pra isso não, porque eu não posso (...) num tenho condições de fazer aquilo que é necessário (...) que vem no livro."

Como não existe uma presença mais sistemática dos técnicos em nível federal em Amaraji, principalmente nas áreas de maior pobreza, como Demarcação, educação em saúde está associada ao trabalho das agentes municipais de saúde. Apesar disso, as limitações das ações educativas continuam sendo apontadas por conta da realidade cotidiana adversa: " $A s$ menina aí, avisa pra gente de saúde (...) do rio, por causa desse problema (...). desse verme mermo, né? Por causa desse problema, assim da água, mas a gente não pode fazer nada".

O discurso popular sobre as ações educativas em saúde expressa o conflito que se dá na incorporação do discurso institucional e de uma prática de necessidade. Este discurso, mesmo sendo entendido como legítimo, é entretanto compreendido dentro do plano do ideal, distoante da realidade vivenciada pela população estudada, o que leva à criação de estratégias de convívio com situações de risco. Estas estratégias parecem ter como objetivo a 
atenuação da contradição entre o discurso oficial e uma realidade adversa.

Assim, a população vale-se de determinados recursos simbólicos, atenuadores da percepção do risco, tais como usar o rio para lavar roupa, mas não para tomar banho; tomar banho de rio, mas não beber de sua água; ficar apenas nas suas margens; dentre outros.

Outro aspecto é que o discurso da população revela um sentimento de impotência diante da realidade e das condições de existência. Discursos estes muitas vezes interpretados por pesquisadores, acadêmicos, políticos e pelo Estado como sendo apático, desmotivado e desmobilizado. Em verdade, não se trata de uma postura de aceitação da realidade, e sim uma sutil estratégia de convivência.

\section{Mobilização comunitária: uma releitura}

Mobilização comunitária é um tipo de participação ativa da população em algum programa oficial que apresenta objetivos específicos, e, no caso das ações IEC/MC/PCDEN, o de modificar comportamentos historicamente estabelecidos e favorecedores dos índices de positividade da esquistossomose.

Tomando-se de empréstimo categorias analíticas da sociologia compreensiva weberiana, podemos afirmar que se pretendia reverter ações tradicionais, ou seja, aquelas fundamentadas em hábitos e costumes arraigados, em particular os banhos de rio (Quintaneiro et al., 1996).

Compreende-se que muitos programas oficiais de intervenção em saúde são estruturados sem uma devida familiaridade com o cotidiano das populações envolvidas, desconsiderando a realidade material, social, psicossocial e cultural da população. Logo, resistência a mudanças em relação aos banhos de rio parece se caracterizar, nessa mesma grade teórica, em 'ações racionais em relação a fins', definidas como aquelas que são organizadas para um objetivo previamente definido, lançando-se mão dos meios necessários ou adequados, ambos avaliados tão claramente quanto possível de seu próprio ponto de vista (Quintaneiro et al., 1996).

No caso dos banhos de rio, os objetivos são a satisfação de necessidades biológicas de sobrevivência, como alimentação, higiene, assim como necessidades psicológicas, lazer. Diante da ausência de saneamento básico, em muitas localidades da Zona Mata de Pernambuco, os banhos de rio tornam-se a única opção possível, sendo, portanto, adequados diante da escassez.
Por outro lado, em termos práticos e operacionais, observa-se que as práticas institucionais, fundamentadas num modelo vertical e medicamentoso, contribuíram para que as ações educativas não se desenvolvessem num movimento mais participativo.

Essa contradição parece nascer historicamente da vocação de controle social das instituições médicas no País, que, desde o século XIX, estiveram atreladas à política do incipiente Estado Nacional (Acioli, 1990). Além disso, nessa organização, estruturou-se uma Medicina de Estado (Foucault, 1980), que incluía o controle médico da vida social. A agência responsável era uma polícia médica, termo criado na Alemanha do século XVIII e cujos princípios se pautavam na responsabilidade do Estado pela saúde da população, controle sanitário sobre todos os aspectos da vida individual e promoção da educação do povo em matéria de saúde (Donnangelo \& Pereira, 1979).

Dessa forma, as instituições médicas no Brasil, quando almejavam programas de Educação em Saúde com metodologias participativas, apresentavam contradições entre discursos e práticas, ou seja, manter um controle social hegemônico e facilitar o desenvolvimento da autonomia comunitária.

Podemos pensar, também, que havia um ensaio de democratização do saber na elaboração de diretrizes participativas contemporâneas ao processo de redemocratização da sociedade brasileira nos anos 80 , mas que esbarravam numa cultura institucional centralizadora e tecnicista. Nesse sentido, os médicos podem ser considerados 'comissários dos grupos dominantes para o exercício das funções da hegemonia (Gramsci, 1982).

Por sua vez, as instituições de saúde são prestigiadas pelas comunidades em razão dos resultados efetivos de algumas ações terapêuticas, muitas decorrentes de um avanço tecnológico e centradas no corpo físico. Entretanto, as populações articulam perifericamente uma releitura dinâmica do processo de hegemonia (expresso, inclusive, nas mensagens pedagógicas oficiais), e que pode ser conceituada como contra-hegemonia (Gramsci, 1982) e se constituindo num dos marcos interpretativos de alguns comportamentos. Empiricamente, podemos considerar como um conceito que facilita compreender a articulação pelos sujeitos entre interdições discursivas oficiais ("não tomar banho de rio", por exemplo) e adequações pragmáticas às necessidades básicas ("tomo banho mas fico na margem”, ou então, "não bebo da água”, de acordo com o usual discurso da população da Zona da Mata). 
O não-cumprimento das diretrizes programáticas dos processos de Educação em Saúde, inclusive mobilização comunitária, usualmente é considerado pelas instituições oficiais como produto de deficiências individuais cognitivas ou atrasos culturais coletivos. Todavia, diante de uma ausência sistemática de avaliações e de auto-avaliações desses mesmos programas, não se organiza um processo educativo que escute essa população e que num plano horizontal facilite construirem-se práticas que atendam a uma visão da saúde enquanto um bloco composto de diversos fatores integrados (culturais, econômicos, políticos, sociais e comportamentais) e fragmentado pela visão tecnicista e especializada do que se chama modernidade (Nunes, 1995).

\section{Conclusões}

A análise documental das ações de educação em saúde na Zona da Mata Sul de Pernambuco, dentro dos objetivos do PCDEN, aponta para algumas distorções que podem ser definidas como estratégias emergenciais e reformulações de prioridades.

Enquanto ações não contempladas nas diretrizes do programa, destaca-se a epidemia do cólera que concentrou as atividades educativas no Distrito de Vitória de Santo Antão, no ano de 1992. Apesar da suposta imprevisibilidade da epidemia, constata-se que são consideradas atividades educativas a distribuição de instrumentos bioterápicos $(53,22 \%)$, superando os $46,78 \%$ do material eminentemente pedagógico, o que representa uma reformulação de prioridade.

Nesse sentido, pode-se deduzir que dentro das ações institucionais ainda são priorizadas estratégias medicamentosas congruentes com um modelo médico tradicional distante de propostas que democratizem o saber.

Características do processo de educação em saúde pouco congruentes com a realidade, no caso da cidade de Amaraji, é que dentre os principais meios auxiliares de ensino utilizados encontra-se a distribuição de folhetos (17.553) e de manuais (3.740) entre 1992 e 1993, parte das ações do Programa de Controle da Esquistossomose. Dados diretos de Amaraji, de acordo com a pesquisa de avaliação das ações (Freese-de-Carvalho \& Acioli, 1996), demonstram que na sede de Amaraji existe uma população de $49,5 \%$ de analfabetos, assim como uma de $60,4 \%$ em distritos como Demarcação, o que os caracterizaria como não leitores.
Outros dados apontam para as oscilações dos índices de positividade para a esquistossomose. Elevadíssimo, em 1977, diminuído entre 1981 e 1982, recrudescido em 1985 e novamente diminuído em 1994. A principal explicação da curva cíclica é o processo de medicalização em massa, uma estratégia já contemplada desde o Programa Especial de Controle da Esquistossomose, a partir do ano de 1977.

Para os agentes de saúde da FNS, essas ações implicam uma divisão funcional entre os guardas-educadores, que orientam a população a aceitar os recursos medicamentosos, e a equipe dos guardas-medicadores, responsável pela distribuição dos medicamentos.

Alguns métodos consistiam numa mobilização das comunidades para se reunirem nas escolas e associações para a realização de palestras educativas. Houve, da parte dos agentes de saúde, críticas às dificuldades de transporte, alojamento e falta de material, assim como ao caráter itinerante das ações, sem um devido estudo prévio das comunidades e nem de avaliações dos processos educativos.

Outro ponto relevante nas análises qualitativas é o de que ações são verticais e diretamente encaminhadas pelo nível central do Ministério da Saúde, dificultando a assunção pelas equipes locais de escolha das comunidades, visando-se um trabalho mais realístico de Educação em Saúde.

Um importante fator limitador das ações educativas, na perspectiva dos técnicos é a precária realidade social, econômica, habitacional e sanitária das populações, reforçadora da necessidade de uso constante do rio para o atendimento às necessidades básicas, inclusive enquanto estratégia de sobrivência.

Essa conjunção de fatores criou como meta das ações educativas uma idéia de que mobilizar era esclarecer e motivar a população a procurar o sistema oficial de saúde, desconsiderando-se sua complexa realidade cultural.

De acordo com a população, as ações educativas estavam concentradas em borrifação, coleta d'água, distribuição de remédios e fixação de croquis nas paredes. Além disso, falouse de palestras em torno de temas como higiene e cuidados materno-infantis, bem como da motivação à participação da comunidade no tratamento nos postos de saúde. Também se observa que existem maiores referências ao trabalho educativo na sede de Amaraji do que nos distritos.

Para a população, existem dificuldades materiais que impedem o cumprimento das orientações contempladas nos folhetos e manuais. 
Por fim, mobilização comunitária trata-se de um projeto discursivo, contemplado em documento nacional que apresenta distâncias operacionais com a realidade local da FNS e com uma prática institucional de medicalização de massa.

O conteúdo teórico dos documentos é congruente com os pressupostos e conceitos de uma pedagogia participativa e de libertação, porém esbarra-se numa espécie de cultura institucional, priorizadora, quase que exclusivamente de métodos biológicos, o que reforça a idéia do controle químico da população, sem uma adequada conscientização social libertadora.

\section{Referências}

ACIOLI, M., 1990. A Fala do Médium e do Doutor: A Construção Histórica do Discurso Médico e Umbandista. Tese de Mestrado, Recife: Centro de Ciências Humanas e Filosofia, Universidade Federal de Pernambuco.

BORDENAVE, J., 1980. Transferencia de Tecnología al Pequeño Agricultor. San José: Iica

DEMO, P., 1995. Metodologia Científica em Ciências Sociais. São Paulo: Editora Atlas.

DONNANGELO, M. C. \& PEREIRA, L., 1979. Saúde e Sociedade. São Paulo: Duas Cidades.

FOUCAULT, M., 1980. Microfísica do Poder. Rio de Janeiro: Forense-Universitária.

FREESE-DE-CARVALHO, E. \& ACIOLI, M., 1996. Pesquisa de Avaliação do Impacto das Ações IEC/ MC no Controle das Doenças Endêmicas em Cinco Estados Brasileiros (Versão Pernambuco). Relatório de Pesquisa, Recife: Banco Mundial/MS/FNS/ NESC/CpAM.

FREIRE, P., 1977. Educação como Prática de Liberdade. Rio de Janeiro: Paz e Terra.

GRAMSCI, A., 1982. Os Intelectuais e a Organização da Cultura. Rio de Janeiro: Civilização Brasileira.

JARA, O., 1995. Concepção Dialética da Educação Popular. São Paulo: Centro de Educação Popular do Instituto Sedes Sapientiae (CEPSIS).

MS (Ministério da Saúde), 1987. Projeto de Controle das Doenças Endêmicas no Nordeste. Programa Oficial. Brasília: Ministério da Saúde.

MS (Ministério da Saúde), 1989a. Projeto de Controle de Doenças Endêmicas no Nordeste. Programa Oficial. Recife: Ministério da Saúde, Diretoria Re- gional de Pernambuco.

MS (Ministério da Saúde), 1989b. Educação em Saúde: Diretrizes. Programa Oficial. Brasília: Ministério da Saúde, Diretoria Regional de Pernambuco.

MS (Ministério da Saúde), 1990. Planejamento para 1990 (Educação em Saúde). Programa de Educação em Saúde. Recife: Ministério da Saúde.

MS (Ministério da Saúde), 1992. Relatório das Atividades Educativas do Distrito de Vitória de Santo Antão. Recife: Ministério da Saúde, Superintendência de Campanhas, Fundação Nacional de Saúde.

MS (Ministério da Saúde), 1993/1994. Relatório das Atividades Educativas e de Mobilização Comunitária junto ao PCE. Recife: Ministério da Saúde, Superintendência de Campanhas, Fundação Nacional de Saúde.

NUNES, E. D., 1995. A questão da interdisciplinaridade no estudo da Saúde Coletiva e o papel das Ciências Sociais. In: Dilemas e Desafios das Ciências Sociais na Saúde Coletiva (A. M. Canesqui, org.), pp.95-113, São Paulo-Rio de Janeiro: Hucitec/Abrasco.

PINTO, J. B., 1982. Planejamento Participativo: Produção do Conhecimento na Ação Comunitária. Belo Horizonte: Encontro de Experiência em Educação em Saúde da Região Centro-Oeste.

QUINTANEIRO, T.; BARBOSA, M. L. O. \& OLIVEIRA, M. G., 1996. Um Toque de Clássicos (Durkheim, Marx e Weber). Belo Horizonte: Editora Ufmg. 